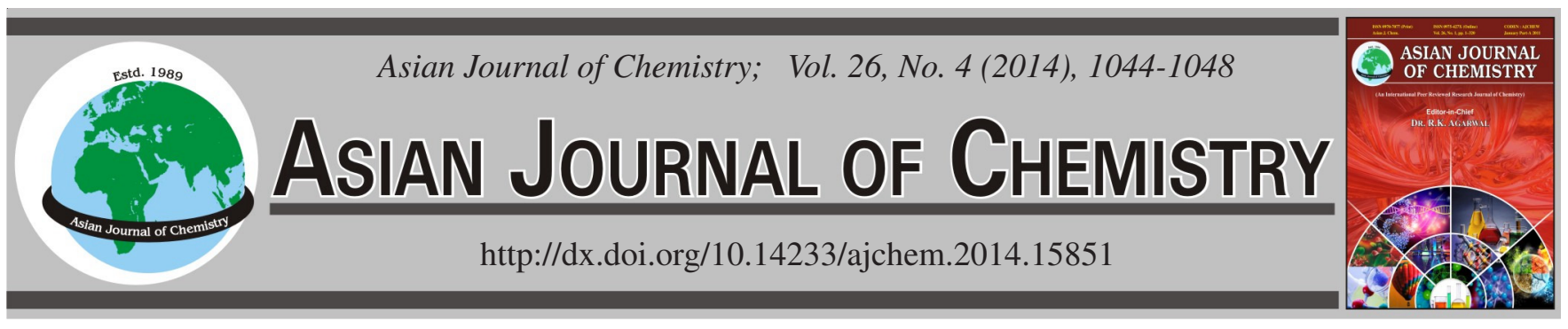

\title{
Enhanced Production of Rhamnolipids by Pseudomonas aeruginosa JQ927360 Using Response Surface Methodology
}

\author{
A. JAMAL ${ }^{1, *}$, M.Z. QuREShi ${ }^{1}$, N. Ali ${ }^{2}$, M.I. Ali ${ }^{2}$ and A. HAMEED ${ }^{2}$
}

${ }^{1}$ Department of Chemistry, Government College University, Lahore, Pakistan

${ }^{2}$ Department of Microbiology, Quaid-i-Azam University, Islamabad, Pakistan

*Corresponding author: E-mail: asifjamall@yahoo.com

Received: 1 June 2013;

Accepted: 30 July 2013;

Published online: 15 February 2014;

AJC-14696

\begin{abstract}
Rhamnolipids are fascinating microbial surfactants having great industrial importance. Present study was focused to investigate the role of some critical fermentation parameters for the production of rhamnolipids from P. aeruginosa JQ927360. The process for the production of rhamnolipids was optimized using central composite design and response surface methodology. The factors subjected for studies were $\mathrm{pH}$, temperature, shaking speed and inoculum size. The maximum rhamnolipids yield of $4.44 \mathrm{~g} / \mathrm{L}$ was achieved at optimum level of process variable i.e., $\mathrm{pH} 7,33{ }^{\circ} \mathrm{C}, 155 \mathrm{rpm}$ and $2.8 \%$ inoculum size. The results of the present investigation suggested that application of mathematical modeling remained very effective to determine optimum reaction conditions and improved the yield of given bioprocess.
\end{abstract}

Keywords: Rhamnolipids, $P$. aeruginosa, Response surface methodology, Biosurfactants, Optimization.

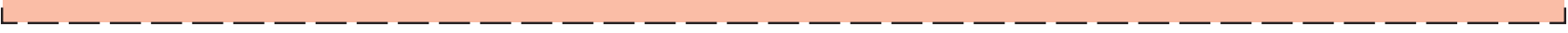

\section{INTRODUCTION}

Rhamnolipids are natural surface active compounds exhibiting broad range of applications such as enhanced oil recovery, bioremediation of polluted sites and antimicrobial agents to kill animal and plant pathogens ${ }^{1,2}$. In addition, rhamnolipid production and applications in various processes comply pursuit of global agenda of sustainable development. Chemically, rhamnolipids are glycolipids containing L-rhamnose and $\beta$-hydroxydecanoic acid residues which are frequently termed as hydrophilic head and hydrophobic tail, respectively ${ }^{3,4}$. They are some of structurally diverse and fascinating biosurfactants produced by different bacterial strains typically from $P$. aeruginos $a^{5}$. Compared to different synthetic surfactants, rhamnolipids show superior physico-chemical properties, biodegradability, less toxicity and can be easily synthesized from renewable sources ${ }^{6}$. Apart from all these advantages, rhamnolipid production is facing certain issues due to their low cellular yield, high cost of raw materials, expensive downstream processing and less information regarding reaction specific conditions ${ }^{7}$.

The production of rhamnolipids from $P$. aeruginosa depends greatly on reaction conditions such as carbon and nitrogen source, temperature, $\mathrm{pH}$, salinity etc. ${ }^{8.9}$. Generally, rhamnolipid production is associated with bacterial growth and substrate utilization pattern ${ }^{10}$. Therefore, optimization and maintenance of the cultivation conditions effecting biosurfactants production have been considered as critical steps for the development of cost effective bioprocess ${ }^{11}$. One dimensional optimization strategies failed to achieve optimum process conditions in limited experimental setups. Further, conventional methods are expensive, laborious and incompetent to explain the interactive effects of process variables ${ }^{12}$. Response surface methodology (RSM) has been considered as most efficient and straightforward statistical approach that allows simultaneous measurement of several process variables; their optimum levels and associated experimental error ${ }^{13}$. Although various efforts have been made for the optimization of rhamnolipids from different bacteria. However, there is scarcity of knowledge regarding the application of RSM for its production. Present research work has evaluated the effect of different process variables for the production of rhamnolipids by an indigenous strain of $P$. aeruginosa. A $2^{4}$ factorial design was employed for optimization of four process variables in order to improve the yield of rhamnolipids from this bacterium.

\section{EXPERIMENTAL}

P. aeruginosa JQ 927360 was collected from Biochemistry Lab, GCU, Lahore. This strain was isolated from petroleum contaminated soil of Missa Keswal Oil Fields located in District 
Jehlum, North Punjab, Pakistan. The strain was showing production of rhamnolipids mixture using glycerol (as carbon source) and reducing the surface tension of the mineral salt media to $26.6 \mathrm{mN} / \mathrm{m}$. The bacterial strain was sub-cultured on nutrient agar plates and used for the production of biosurfactants in subsequent experiments.

Fermentation media and inoculum preparation: For biosurfactant production, fermentation media consists of following ingredients (g/L) $\mathrm{NaNO}_{3}, 5 \mathrm{~g}, \mathrm{~K}_{2} \mathrm{PHO}_{4} 3 \mathrm{~g}, \mathrm{NaH}_{2} \mathrm{PO}_{4}$, $2 \mathrm{~g}, \mathrm{MgSO}_{4} \cdot 7 \mathrm{H}_{2} \mathrm{O}, 0.4 \mathrm{~g}, \mathrm{FeSO}_{4} 0.004 \mathrm{~g}$ and $3 \%$ of glycerol was added as sole source of carbon. The aforementioned media was supplemented with $1 \mathrm{~mL}$ of micronutrients solution containing; $\mathrm{ZnSO}_{4} \cdot 7 \mathrm{H}_{2} \mathrm{O}, \mathrm{CuSO}_{4} \cdot 5 \mathrm{H}_{2} \mathrm{O}, \mathrm{CoCl}_{2} \cdot 6 \mathrm{H}_{2} \mathrm{O}$ and $\mathrm{NaMoO}_{4} \cdot \mathrm{H}_{2} \mathrm{O}, \mathrm{MnSO}_{4} \cdot \mathrm{H}_{2} \mathrm{O}, \mathrm{KCl}$. The other reaction conditions such as $\mathrm{pH}$, temperature, $\mathrm{rpm}$ and inoculum size was adjusted according to the design of experiment (Table-1). The fermentation was carried out for $96 \mathrm{~h}$ and all results were recorded after $72 \mathrm{~h}$ of incubation period.

Inoculum was prepared using the aforementioned media. The $\mathrm{pH}$ of the medium was adjusted at 7 and after sterilization, a loop full of bacteria was inoculated the aforementioned media into $250 \mathrm{~mL}$ flask. The flask was then kept under continuous shaking at $160 \mathrm{rpm}$ and $37^{\circ} \mathrm{C}$ for $48 \mathrm{~h}$.

Estimation of rhamnolipid: The rhamnolipids were estimated calorimetrically by the method of Chandrasekaran and Be-Miller ${ }^{14}$. The supernatant was obtained by centrifugation of culture broth at $10,000 \mathrm{rpm}$ for $20 \mathrm{~min} .333 \mu \mathrm{L}$ of the culture supernatant was then extracted using diethyl ether as solvent and collected in a separate tube. The solvent was evaporated and re-suspended by addition of $0.5 \mu \mathrm{L}$ deionized water. $100 \mu \mathrm{L}$ of this solution was mixed with freshly prepared orcinol reagent. The mixture was allowed to react $80{ }^{\circ} \mathrm{C}$ for $0.5 \mathrm{~h}$ and after cooling to room temperature, the absorbance was measured at $421 \mathrm{~nm}$. The results were than analyzed by comparison with a standard curve of the L-rhamnose.

Experimental design and statistical: Design of experiment is frequently used method to study the individual and interactive effects of process parameters in a given bioprocess ${ }^{15}$. In present research, a $2^{4}$ level central composite design (CCD) was made for four selected process variable namely, $\mathrm{pH}$, temperature, shaking speed (rpm) and inoculum size using Design Expert ${ }^{\circledR}$. The software generated a full length randomized factorial design with 30 experimental runs. The factors with their respective levels are presented in the Table-1. All of the experiments were carried out in triplicate and a mean of three reading was processed for statistical analysis. Rhamnolipid concentrations $(\mathrm{g} / \mathrm{L})$ were selected as response. The data obtained after performing experiments was analyzed using Design Expert 8.0.1.7 and multiple regressions was employed to evaluate effect of process parameters.

\section{RESULTS AND DISCUSSION}

The effect of different culture conditions on the production on the production of rhamnolipids by $P$. aeruginosa was investigated by employing Centeral Composite Design (CCD). Four environmental factors viz. $\mathrm{pH}$, temperature, agitation speed (rpm) and inoculum size were subjected for studies for the optimum production of rhamnolipid. The values of rhamnolipids in response to different levels of independent variables are presented in the Table- 2 . The model was fitted to the response with a confidence level of $99.99 \%$. The significance of the process variable was determined by their $p$-values. For rhamnolipids, $\mathrm{X}_{1}, \mathrm{X}_{2}, \mathrm{X}_{3}, \mathrm{X}_{4}, \mathrm{X}_{1}, \mathrm{X}_{2}, \mathrm{X}_{1}{ }^{2}, \mathrm{X}_{2}^{2}, \mathrm{X}_{3}{ }^{2}$ and $\mathrm{X}_{4}^{2}$ were identified as significant model terms and their respective $p$-values are presented in (Table-3). The software suggested a second order polynomial quadratic equation to explain the effect of dependant variables on the response (eqn. 1).

TABLE-2

EXPERIMENTAL DESIGN AND CORRESPONDING RESULTS IN TERMS OF RHAMNOLIPIDS (g/L). THE FACTORS AND THEIR RESPECTED LEVELS ARE EXPRESSED IN ACTUAL FORMS

\begin{tabular}{|c|c|c|c|c|c|}
\hline \multirow{2}{*}{ Runs } & $\mathrm{pH}$ & Temp. & $\mathrm{rpm}$ & $\begin{array}{l}\text { Inoculum } \\
\text { size }\end{array}$ & $\begin{array}{l}\text { Rhamnolipids } \\
(\mathrm{g} / \mathrm{L})\end{array}$ \\
\hline & $\mathrm{x}_{1}$ & $\mathrm{x}_{2}$ & $x_{3}$ & $\mathrm{x}_{4}$ & $\mathrm{Y}_{1}$ \\
\hline 1 & 6.50 & 42.0 & 180 & 1.0 & 1.02 \\
\hline 2 & 8.75 & 34.5 & 150 & 2.5 & 0.34 \\
\hline 3 & 7.25 & 34.5 & 150 & 5.5 & 1.91 \\
\hline 4 & 6.50 & 27.0 & 120 & 4.0 & 1.82 \\
\hline 5 & 8.00 & 27.0 & 120 & 4.0 & 1.68 \\
\hline 6 & 6.50 & 42.0 & 180 & 4.0 & 1.45 \\
\hline 7 & 8.00 & 42.0 & 180 & 1.0 & 1.01 \\
\hline 8 & 7.25 & 19.5 & 150 & 2.5 & 0.51 \\
\hline 9 & 5.75 & 34.5 & 150 & 2.5 & 1.61 \\
\hline 10 & 8.00 & 27.0 & 120 & 1.0 & 1.31 \\
\hline 11 & 7.25 & 34.5 & 150 & 2.5 & 2.89 \\
\hline 12 & 7.25 & 34.5 & 150 & 0.5 & 0.63 \\
\hline 13 & 8.00 & 42.0 & 180 & 4.0 & 1.56 \\
\hline 14 & 7.25 & 34.5 & 150 & 2.5 & 2.76 \\
\hline 15 & 8.00 & 42.0 & 120 & 1.0 & 0.65 \\
\hline 16 & 6.50 & 27.0 & 180 & 4.0 & 2.45 \\
\hline 17 & 7.25 & 34.5 & 150 & 2.5 & 2.82 \\
\hline 18 & 7.25 & 34.5 & 210 & 2.5 & 1.82 \\
\hline 19 & 7.25 & 34.5 & 90 & 2.5 & 0.64 \\
\hline 20 & 8.00 & 27.0 & 180 & 4.0 & 1.82 \\
\hline 21 & 7.25 & 34.5 & 150 & 2.5 & 2.97 \\
\hline 22 & 6.50 & 27.0 & 120 & 1.0 & 2.19 \\
\hline 23 & 6.50 & 42.0 & 120 & 1.0 & 0.78 \\
\hline 24 & 8.00 & 27.0 & 180 & 1.0 & 0.91 \\
\hline 25 & 6.50 & 27.0 & 180 & 1.0 & 2.84 \\
\hline 26 & 6.50 & 42.0 & 120 & 4.0 & 0.81 \\
\hline 27 & 7.25 & 34.5 & 150 & 2.5 & 2.71 \\
\hline 28 & 7.25 & 49.5 & 150 & 2.5 & 0.00 \\
\hline 29 & 7.25 & 34.5 & 150 & 2.5 & 2.83 \\
\hline 30 & 8.00 & 42.0 & 120 & 4.0 & 1.02 \\
\hline
\end{tabular}

TABLE-1

VARIABLES AND THEIR RESPECTIVE LEVELS

\begin{tabular}{lcccccc}
\hline \multirow{2}{*}{\multicolumn{1}{c}{ Variables }} & \multirow{2}{*}{ Codes } & \multicolumn{5}{c}{ Levels of the variables } \\
\cline { 3 - 7 } & & -2 & -1 & 0 & +1 & +2 \\
\hline $\mathrm{pH}$ & $\mathrm{X}_{1}$ & 4.75 & 6.0 & 7.25 & 8.50 & 9.75 \\
Temperature $\left({ }^{\circ} \mathrm{C}\right)$ & $\mathrm{X}_{2}$ & 19.5 & 27.0 & 34.5 & 42.0 & 49.5 \\
Shaking speed $(\mathrm{rpm})$ & $\mathrm{X}_{3}$ & 50 & 100 & 150 & 200 & 250 \\
Inoculum size $(\%)$ & $\mathrm{X}_{4}$ & 0.5 & 1.0 & 2.5 & 4.0 & 5.5 \\
\hline
\end{tabular}




\begin{tabular}{cccccc}
\hline \multicolumn{7}{c}{ TABLE-3 } \\
& \multicolumn{7}{c}{ ANOVA OF SELECTED MODEL TERMS } \\
\hline Source & Sum of squares & Degree of freedom & Mean square & F-Value & $p$-Value \\
\hline Regression & 20.15 & 10 & 2.01 & 15.51 & $<0.0001$ \\
$\mathrm{X}_{1}$ & 1.55 & 1 & 1.55 & 11.91 & 0.0027 \\
$\mathrm{X}_{2}$ & 2.40 & 1 & 2.40 & 18.49 & 0.0004 \\
$\mathrm{X}_{3}$ & 0.93 & 1 & 0.93 & 7.16 & 0.0149 \\
$\mathrm{X}_{4}$ & 0.91 & 1 & 0.91 & 7.01 & 0.0159 \\
$\mathrm{X}_{1} \mathrm{X}_{2}$ & 0.96 & 1 & 0.96 & 7.37 & 0.0138 \\
$\mathrm{X}^{2_{1}}$ & 4.05 & 1 & 4.05 & 31.20 & $<0.0001$ \\
$\mathrm{X}^{2}$ & 8.74 & 1 & 8.74 & 67.26 & $<0.0001$ \\
$\mathrm{X}^{2}$ & 2.16 & 1 & 2.16 & 16.61 & 0.0006 \\
$\mathrm{X}^{23}$ & 2.65 & 1 & 2.65 & - & 0.0002 \\
Residual & 2.47 & 19 & 0.13 & 20.34 & - \\
Lack of fit & 2.43 & 14 & 0.17 & - & 0.0018 \\
Pure error & 0.043 & 5 & 8.52 & - & - \\
Cor total & 22.62 & 29 & - & -
\end{tabular}

$\mathrm{R}^{2}=0.8909$, Adj. $\mathrm{R}^{2}=0.8334$, coffcient of varience $=22.56 \%$, Adeq precision $=13.24, \mathrm{X}_{1}=\mathrm{pH}, \mathrm{X}_{2}=$ Temperature, $\mathrm{X}_{3}=$ Shaking speed, $\mathrm{X}_{4}=$ Inoculum size.

$\mathrm{Y} 1=-39.06019+8.24043\left(\mathrm{X}_{1}\right)+0.30289\left(\mathrm{X}_{2}\right)+0.11776$ $\left(X_{3}\right)-0.59047\left(X_{4}\right)+0.043489\left(X_{1} X_{2}\right)-3.62778\left(X_{1} X_{3}\right)+$ $0.15033\left(\mathrm{X}_{1} \mathrm{X}_{4}\right)+1.53889\left(\mathrm{X}_{2} \mathrm{X}_{3}\right)+3.58889\left(\mathrm{X}_{2} \mathrm{X}_{4}\right)+1.31389$ $\left(X_{3} X_{4}\right)-0.68352\left(X_{1}^{2}\right)-0.010035\left(X_{2}^{2}\right)-3.11644\left(X_{3}^{2}\right)-$ $0.13810\left(\mathrm{X}_{4}^{2}\right)$

where, $\mathrm{Y} 1$ is rhamnolipid concentration, $\mathrm{X}_{1}, \mathrm{X}_{2}, \mathrm{X}_{3}$ and $\mathrm{X}_{4}$ corresponds to $\mathrm{pH}$, temperature, shaking speed (rpm) and inoculum size, respectively.

Analysis of varience (ANOVA) test was employed to validate the model significance (Table-3). The F-values of the model was found to be 15.51 which implied our model was significant and there is only $0.01 \%$ chances that larger Model F-value could occur due to noise. The adequency of the models were evaluated with reference to the coefficient of variance (CV) and coeffcient of regression $\left(\mathrm{R}^{2}\right)$. The $\mathrm{CV}$ value $20.26 \%$ indicated a high degree of percision and reliability of the experimental data (Table-3). Similarly, $\mathrm{R}^{2}$ vlaues was 0.89 which indicates that predicted and experimental values are in close confirmity to each other and $89 \%$ of the variability in the responses could be explained by the model. The adequate percision measured the signal to niose ratio and it was $13.24 \%$ corresponding an adequate signal. Fig. 1 demonstrated relationship between the predicted and actual values of rhamnolipids. Both of these values were adjusted in close proximity of the centeral reference line indicating that the values obtained after experimentation were somewhat similar to those predicted by the model.

Results indicated that rhamnolipids production by $P$. aeruginosa was supressed when the $\mathrm{pH}$ of the medium was lower than 6.5. Similarly, there was observed a gradual decrease in production of rhamnolipids with increase in $\mathrm{pH} \geq$ 7.5. So, rhamnolipids yield was comparatively high within a $\mathrm{pH}$ range of 6.5-7.5 and it was maximum at $\mathrm{pH}$ 7. This suggested that the bacterial strian was highly senstive to $\mathrm{pH}$ for rhamnolipid production (Fig. 2A-C). Similarly, the rhamnolipids production proved to be directly related to hydrogen ion concentration of the culture media ${ }^{16}$ and its synthesis was maximum at $\mathrm{pH} 6.5$ by $P$. aeruginosa. In another case, the yield of rhamnolipids was maximum at $\mathrm{pH} 7$ by $P$. aeruginosa $\mathrm{UG} 2$, whereas, it was slightly decreased at acidic

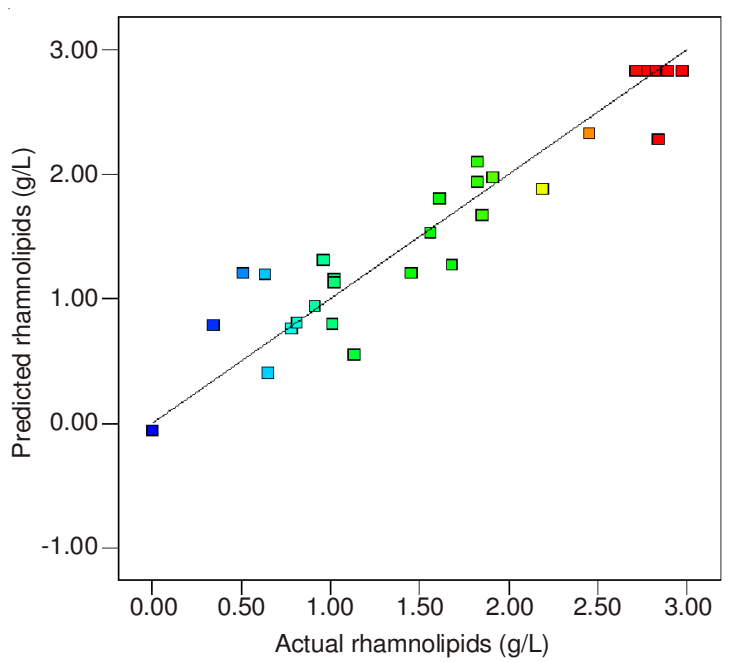

Fig. 1. Actual vs predicted rhamnolipids concentration

conditions ${ }^{17}$. In another study, it was found that maximum rhamnolipids produced from Pseudomonas aeruginosa RS29 between the $\mathrm{pH} 7-8^{18}$. Our findings suggested that for the optimum production of biosurfactant, $\mathrm{pH}$ needs to be controlled as it has a direct relation with the growth and metabolism of the bacteria.

Pseudomonas aeruginosa was able to grow in a broad range of temperatures $\left(25-42^{\circ} \mathrm{C}\right)$, with a varying rhamnolipids synthetic abilities. Temperature $<25->37^{\circ} \mathrm{C}$ proved to be limiting for the synthesis of rhamnolipid. It was compeletely ceased at a temperature $\geq 45^{\circ} \mathrm{C}$. The highest yield was observed at $32{ }^{\circ} \mathrm{C}(\mathrm{Fig} .2 \mathrm{~A}, 2 \mathrm{D}, 2 \mathrm{E})$. The regulation of bacterial growth and metablosim has been directly related to the temperature. The production of rhmanolipids $P$. aeruginosa was maximum between $32-34{ }^{\circ} \mathrm{C}^{19}$. Whereas, in another strain the optimum yield of rhamnolipids was at temperature range of $30-40^{\circ} \mathrm{C}^{20}$. This varying production of rhamnolipids has been associated with diverse metabolic capabilities in different strains of $P$. aeruginosa ${ }^{21}$.

Agitation proved to be an important factor on the metabolism of bacteria. Similar observation were made in the present study (Fig. 2 B, 2D and 2F). Maximum concentration of the rhamnolipids was detected when the agaitation speed 
remained in the limit of 140-160. Less biosurfactants were released when rpm fluctuated from these values. The 3-D response surface plots showed that maximum biosurfactants were produced at the center of the curvature at $155 \mathrm{rpm}$. It is reported that growth and rhamnolipids production from $P$. aeruginosa was enhanced up to $80 \%$ when agitation rate increased from 50 to $200^{22,23}$. Microbial cultures can alter their cell morphology and switch their metabolic pathways under stationary and continuous shaking conditions. Agitation speed affects the rate of mass tranfer efficiency of both oxygen and media components and plays a crucial role in the growth and metabolism of the aerobic bacteria such as $P$. aeruginosa in fermentation $^{24,25}$.

$2(A)$

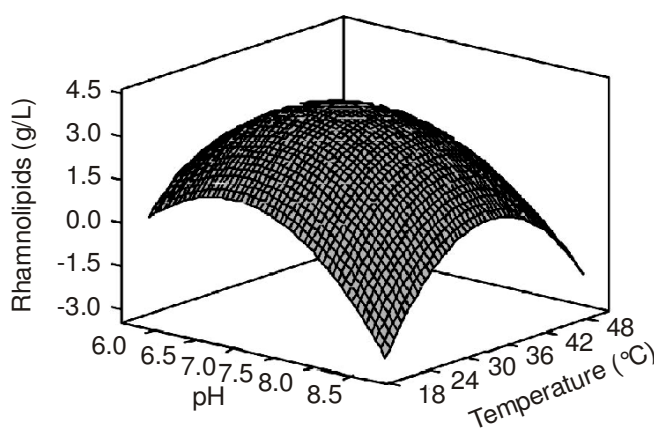

$2(\mathrm{C})$

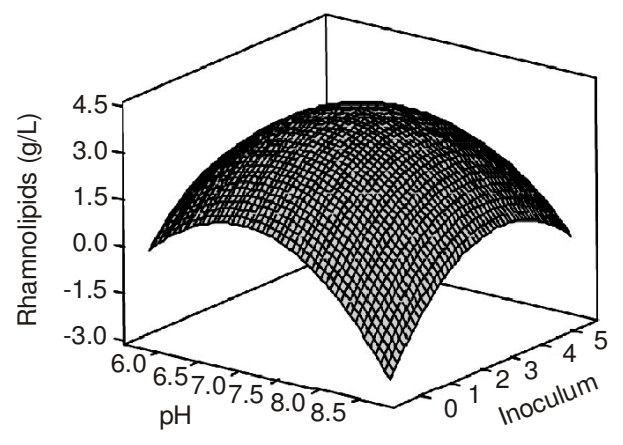

2(E)

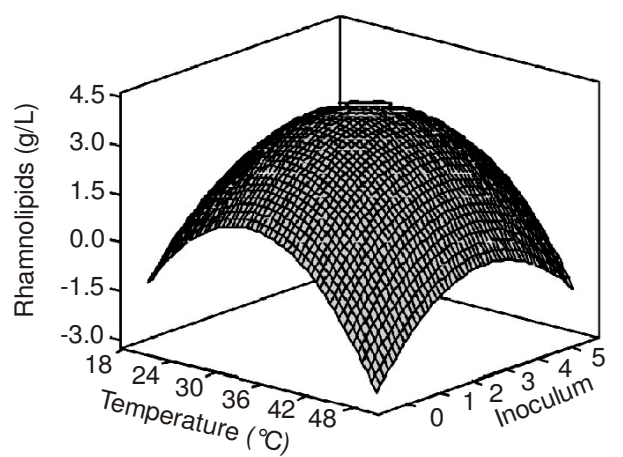

Inoculum size is another improtant parameter used in bioprocesses technology for the production of microbial metabolites. Our results also indicated that rhamniolipids poroduction was directely related to inoculum size or intial bacterial culture density. 3-D respose surface plots represent that low bacterial growth was established when the inoclum size was $\leq 2 \%$ and $\geq 3 \%$ (Fig. 2C, $2 \mathrm{E}, 2 \mathrm{~F}$ ). The maximum yield of rhamnolipids was achieved at the central point of the response plot when the inoculum size was $2.8 \%$. Population density plays an important role in regulating the activities and metabolism of the micoorgansism in a particular system. The rhamnolipids production in $P$. aeruginosa proved to be associated with bacterial density, Quroum sensing and specific

2(B)

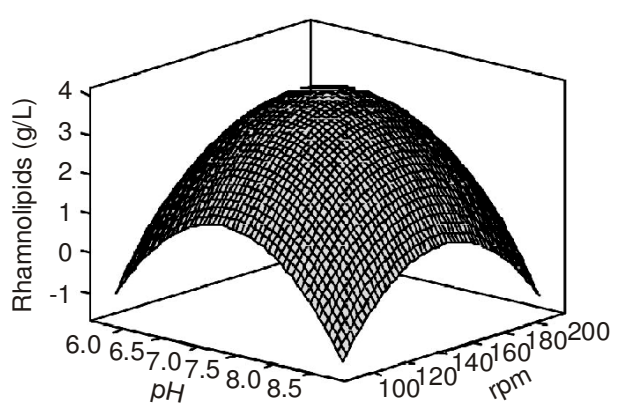

2(D)

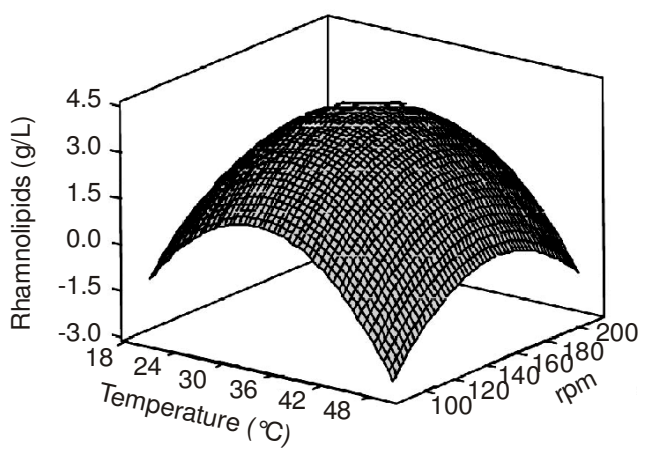

2(F)

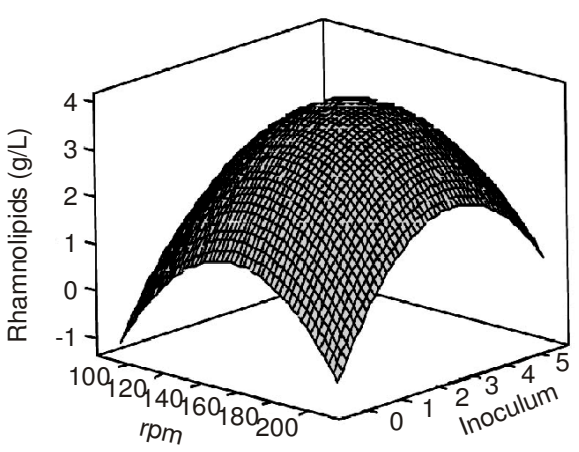

Fig. 2. Three dimensional response surface plots for Rhamnolipids production under the effect of four process variables. (2A-) Rhamnolipids production under the effect of $\mathrm{pH}$ and temperature (2B) Rhamnolipids production under the effect of $\mathrm{pH}$ and rpm (2C-) Rhamnolipids production under the effect of $\mathrm{pH}$ and inoculum (2D-) Rhamnolipids production under the effect of temperature and rpm (2E) Rhamnolipids production under the effect of temperature and inoculum $(2 \mathrm{~F}-)$ rhamnolipids production under the effect of rpm and inoculum 
signilling molecules that initiate specific metabolic pathway of the cells ${ }^{26,27}$. Besides, increase in inoculum size beyond certain creates severe competition among bacteria leading to change in metabolism toward survival pattern. Our results indicated that at a specific polulation density of $P$. aeruginosa strain secreted maximum rhamnolipids, therefore, incoulum size must be considered for designing bio-process for the production of rhamnolipids.

It was also observed that among all possible quadric interations, $\mathrm{pH}$ and temperature were the most influencial for rhamnolipids production. The $p$-value corresponded to this interaction was found to be in the significant range (Table-3). Similarly, putrefaction plot also demonstrated that $\mathrm{pH}$ and temperatre imparted greater impact within this system (Fig. 3). In contrast, other combinations had low effects in the given process and were statistically non-significant. Various studies addressed the role of $\mathrm{pH}$ and temperature for bacterial growth and biosurfactants production. Guerra Santos et al. ${ }^{19}$, found that maximum rhamnolipids were secreted by $P$. aeruginosa when the $\mathrm{pH}$ of the system was between 6.2-6.4 and temperature range of $32-34^{\circ} \mathrm{C}$. Interactive optimization strategies are demonstrated as the most efficient tools for the optimization of the important process variables. The optimization results revealed that the range of the variables selected for the studies were appropriate. Precisely, after optimization the amount of biosurfactant production by strain JQ increased as compared to un-optimization conditions from 2.27 to $4.44 \mathrm{~g} / \mathrm{L}$.

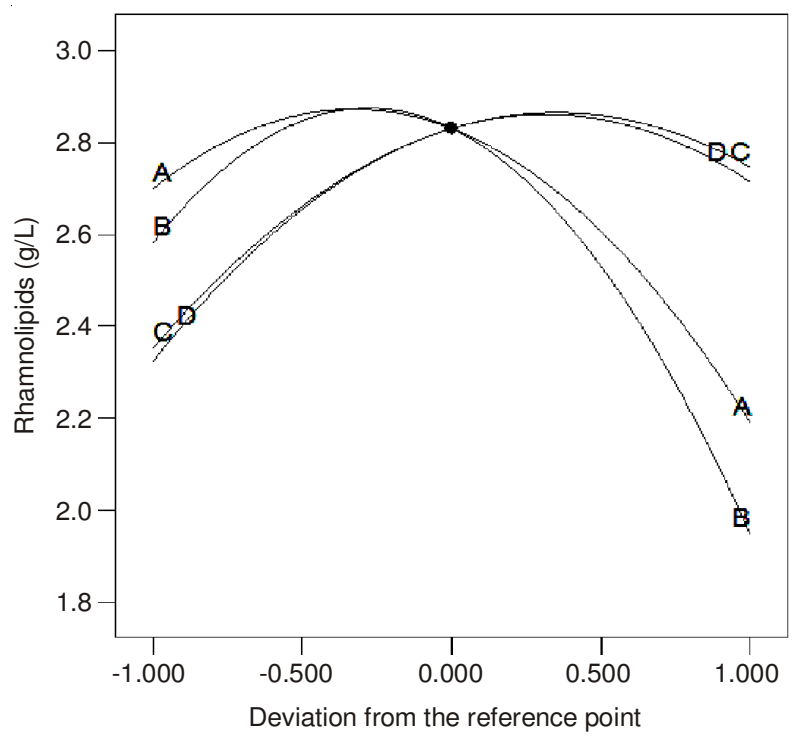

Fig. 3. Perturbation plot for rhamnolipids production

\section{Conclusion}

In current studies effect of some critical process parameters on the production of rhamnolipids by $P$. aeruginosa was investigated. The optimum reaction conditions pertaining to highest rhamnolipids yield were found to be $\mathrm{pH} 7,34^{\circ} \mathrm{C}$, $155 \mathrm{rpm}$ and $2.8 \%$ inoculum size. Under these conditions $4.44 \mathrm{~g} / \mathrm{L}$ of the biosurfactant was produced after $72 \mathrm{~h}$ of fermentation. The response surface methodology is proved to be an efficient tool for improving process efficiency.

\section{REFERENCES}

1. I.M. Banat, A. Franzetti, I. Gandolfi, G. Bestetti, M.G. Martinotti, L. Fracchia, T.J. Smyth and R. Marchant, Appl. Microbiol. Biotechnol., 87, 427 (2010).

2. L. Rodrigues, I.M. Banat, J. Teixeira and R. Oliveira, J. Antimicrob. Chemother., 57, 609 (2006).

3. J.R. Edwards and J.A. Hayashi, Arch. Biochem. Biophys., 111, 415 (1965).

4. A.M Abdel-Mawgoud, F. Lépine and E .Dézie, Appl. Microbiol. Biotechnol., 86,1323 (2010).

5. J.Y. Wu, K.L. Yeh, W.B. Lu, C.L. Lin and J.S. Chang, Bioresour. Technol., 99, 1157 (2008).

6. P. Vatsa, L. Sanchez, C. Clement, F. Baillieul and S. Dorey, Int. J. Mol. Sci., 11, 5095 (2010).

7. M. Heyd, A. Kohnert, T.H. Tan, M. Nusser, F. Kirschhofer, G. BrennerWeiss, M. Franzreb and S. Berensmeier, Anal. Bioanal. Chem., 391, 1579 (2008).

8. M.M. Müller, C. Syldatk and R. Hausmann, Appl. Microbiol. Biotechnol., 87, 167 (2010).

9. J.R. Sousa, J.A.C. Correa, J.J.L. Martins, V.M.M. Melo, A.J.G. Cruz and L.R.B. Gonçalves, J. Biotechnol., 150, 395 (2010).

10. M.H. Choi, J. Xu, M. Gutierrez, T. Yoo, Y.H. Cho and S.C. Yoon, J. Biotechnol., 151, 30 (2011).

11. A.R. Najafi, M.R. Rahimpour, A.H. Jahanmiri, R. Roostaazad, D. Arabian and Z. Ghobadi, Chem. Eng. J., 163, 188 (2010).

12. W.A.K. Lotfy, M. Ghanem and E.R. El-Helow, Bioresour. Technol., 98, 3470 (2007).

13. J. Chen, P.T. Huang, K.Y. Zhang and F.R. Ding, J. Appl. Microbiol., 112, 660 (2012).

14. E.V. Chandrasekaran and J.N. BeMiller, in eds.: R.L. Whistler and J.N. Bemiller, Methods in Carbohydrate Chemistry, Academic Press, New York (1980).

15. D.C. Montgomery, Design and Analysis of Experiments, John Wiley \& Sons, New York, pp. 427-510 (1997).

16. C. Chayabutra, J. Wu and L. Ju, Biotechnol. Bioeng., 72, 25 (2001).

17. J.C. Mata-Sandoval, J. Karns and A. Torrents, Microbiol. Res., 155, 249 (2001).

18. R.R. Saikia, S. Deka, M. Deka and H. Sarma, J. Basic Microbiol., 52, 446 (2012).

19. L.H. Guerra-Santos, O. Kappeli and A. Fiechter, Appl. Microbiol. Biotechnol., 24, 443 (1986).

20. M.M. Müller, B. Hörmann, M. Kugel, C. Syldatk and R. Hausmann, Appl. Microbiol. Biotechnol., 89, 585 (2011).

21. F. Dubois-Brissonnet, C. Malgrange, L. Guérin-Méchin, B. Heyd and J.Y. Leveau, Int. J. Food Microbiol., 55, 79 (2000).

22. Y.H. Wei, C.L. Chou and J.S. Chang, Biochem. Eng. J., 27, 146 (2005).

23. C.G Kumar, S.K. Mamidyala, P. Sujitha, H. Muluka and S. Akkenapally, Biotechnol. Progr., 6, 1507 (2012).

24. D.G. Davies, A.M. Chakrabarty and G.G. Geesey, Appl. Environ. Microbiol., 59, 1181 (1993).

25. D.G. Davies and G.G. Geesey, Appl. Environ. Microbiol., 61, 860 (1995).

26. E. Deziel, S. Gopalan, A.P. Tampakaki, F. Lepine, K.E. Padfield, M. Saucier, G. Xiao and L.G. Rahme, Mol. Microbiol., 55, 998 (2005).

27. J.W. Schertzer, M.L. Boulette and M. Whiteley, Trends Microbiol., 17, 189 (2009). 